\title{
Should We Use Volume-Targeted Noninvasive Ventilation in Patients With Acute Hypercapnic Respiratory Failure?
}

There is strong evidence that the use of noninvasive ventilation (NIV) as first-line therapy is beneficial in patients with severe COPD exacerbation in as much as it reduces endotracheal intubation and mortality. ${ }^{1,2}$ In acute hypercapnic respiratory failure, NIV provides positive pressure that increases tidal volume and alveolar ventilation, with subsequent improvement of oxygenation and reduction of hypercapnia. The most commonly used modes to apply NIV are pressure-limited, ${ }^{3}$ either pressure support ventilation when ICU ventilators are used or bi-level positive airway pressure when home or dedicated NIV ventilators are used. ${ }^{4}$ The resulting minute ventilation is mainly determined by patient-triggered breaths and by preset levels of pressure support above PEEP using pressure support ventilation or the difference between inspiratory positive airway pressure (IPAP) and end-expiratory positive airway pressure (EPAP) using bi-level positive airway pressure.

The load of respiratory muscles is particularly high during a COPD exacerbation..$^{5,6}$ The marked increase in work of breathing is due to the worsening of expiratory flow limitation, resulting in lung hyperinflation and intrinsic PEEP. As a result, the patient needs to overcome intrinsic PEEP to trigger the ventilator and to generate inspiratory flow and tidal volume. Applying external PEEP and pressure support (or IPAP and EPAP) both help to reduce patient effort and to increase tidal volume. ${ }^{7}$ Preset pressure support and magnitude of patient effort are the 2 main determinants of the resulting tidal volume. In acute hypercapnic respiratory failure, tidal volume cannot be guaranteed under pressure-limited modes because airway resistance, intrinsic PEEP, patient effort, and/or respiratory drive may vary. ${ }^{8}$ In the case of alterations of mechanical properties under NIV, the breathing pattern could result in short and small breaths despite a high central respiratory drive. ${ }^{6}$

A possible alternative helping to maintain a constant tidal volume during NIV could be the use of a volumetargeted mode. This hybrid mode continuously controls

\footnotetext{
The authors have disclosed no conflicts of interest.
}

Correspondence: Jean-Pierre Frat MD, CHU de Poitiers, Service de Réanimation Médicale, 2 Rue de la Milétrie, CS 90577, 86021 Poitiers Cedex, France. E-mail: jean-pierre.frat@chu-poitiers.fr.

DOI: $10.4187 /$ respcare. 05190 tidal volume by automatic adjustment of pressure support level. Tidal volume remains constant regardless of the changes in respiratory conditions (eg, in the case of an

See the Original Study on Page 1440

increase in airway resistance, intrinsic PEEP, or a decrease in patient effort). The main drawback reported with a volume-targeted mode is a paradoxical decrease in pressure support in the case of an increase in ventilatory demand. ${ }^{9}$ Indeed, in the case of an increase in tidal volume due to a rough increase in patient effort, the response of the ventilator will be an inadequate reduction in pressure support to reduce the resulting tidal volume. However, during a severe COPD exacerbation, the main consequence of alterations in respiratory mechanics is a reduction in patient effort and in tidal volume. ${ }^{5,6} \mathrm{~A}$ volume-targeted mode may theoretically avoid the risk of reduced tidal volume and minute ventilation. A previous case-control study reported benefits in 11 subjects with COPD and hypercapnic encephalopathy treated with volume-targeted mode as compared with 11 matched subjects treated with pressure-limited mode. ${ }^{10}$ The use of volume-targeted mode facilitated rapid recovery of consciousness and decrease in $\mathrm{P}_{\mathrm{aCO}_{2}}$. As expected, tidal volumes were significantly higher with volume-targeted mode than with pressure-limited mode without a significant increase in leaks.

In this issue of Respiratory CARE, Cao et al ${ }^{11}$ report the results from a multi-center randomized controlled trial comparing pressure-limited NIV (IPAP up to $25 \mathrm{~cm} \mathrm{H}_{2} \mathrm{O}$ to obtain a tidal volume of $8-10 \mathrm{~mL} / \mathrm{kg}$ of predicted body weight) versus volume-targeted NIV (IPAP ranging from 10 to $25 \mathrm{~cm} \mathrm{H}_{2} \mathrm{O}$ to target a tidal volume of $10 \mathrm{~mL} / \mathrm{kg}$ with) in 58 subjects with acute hypercapnic respiratory failure $\left(\mathrm{P}_{\mathrm{aCO}}>45 \mathrm{~mm} \mathrm{Hg}\right.$ with a pH between 7.25 and 7.35). Among them, $78 \%$ of subjects had underlying COPD. In both groups, the $\mathrm{P}_{\mathrm{aCO}}$ was significantly reduced $6 \mathrm{~h}$ after NIV (primary outcome) to a similar extent regardless of the ventilatory mode. Neither other physiologic parameters ( $\mathrm{pH}$, breathing frequency, or accessory muscle use) nor clinical outcomes (rates of intubation and mortality, NIV duration, or length of hospital stay) differed between groups. The subjects receiving volume-targeted ventilation had significantly less variance of tidal volume than those 
receiving pressure-limited NIV, with a subsequent large variance of IPAP levels. However, the mean tidal volumes were very close in the 2 groups: $583 \pm 70 \mathrm{~mL}$ in the volumetargeted mode versus $581 \pm 132 \mathrm{~mL}$ in the pressure-limited mode. The daily doses of NIV as well as the amount of leaks and tolerance to NIV were similar in both groups.

This study ${ }^{11}$ has several strengths, including well-balanced baseline subject characteristics and prespecified criteria for intubation or weaning of NIV. The weaknesses include a small sample of subjects with a relatively low severity, as indicated by the low breathing frequency around 22-23 breaths/min at baseline and a $\mathrm{pH}$ between 7.25 and 7.35 (inclusion criteria). Negative findings of this study lead us to consider the usual pressure-limited modes as the first strategy of NIV in the management of subjects with acute hypercapnic respiratory failure. Indeed, tidal volumes were similar between groups and did not differ significantly over time, suggesting that few episodes of worsening or changes in subject mechanical respiratory properties occurred during the NIV sessions. An adequate tidal volume is the cornerstone of NIV efficiency in acute hypercapnic respiratory failure, whatever the mode used, and the implementation of an NIV protocol driven by caregivers (nurses/respiratory therapists) with the aim of targeting adequate tidal volume by adjusting the pressure support level may be associated with good outcomes. ${ }^{12}$

We cannot exclude the possibility that a volume-targeted mode may be beneficial in patients with acute and marked alterations of respiratory mechanical properties or in the case of hypercapnic encephalopathy with altered respiratory drive. Volume-targeted NIV appears to be feasible and well-tolerated, with the advantage of limiting variance of tidal volume over time with similar effect on hypercapnia.

Jean-Pierre Frat MD Service de Réanimation Médicale CHU de Poitiers INSERM, CIC-1402, Équipe 5 ALIVE Université de Poitiers Poitiers, France

Arnaud W Thille MD PhD Service de Réanimation Médicale CHU de Poitiers
INSERM, CIC-1402, Équipe 5 ALIVE

Université de Poitiers

Poitiers, France

\section{REFERENCES}

1. Brochard L, Mancebo J, Wysocki M, Lofaso F, Conti G, Rauss A, et al. Noninvasive ventilation for acute exacerbations of chronic obstructive pulmonary disease. N Engl J Med 1995;333(13):817-822.

2. Keenan SP, Sinuff T, Cook DJ, Hill NS. Which patients with acute exacerbation of chronic obstructive pulmonary disease benefit from noninvasive positive-pressure ventilation? A systematic review of the literature. Ann Intern Med 2003;138(11):861-870.

3. Esteban A, Frutos-Vivar F, Muriel A, Ferguson ND, Peñuelas O, Abraira V, et al. Evolution of mortality over time in patients receiving mechanical ventilation. Am J Respir Crit Care Med 2013;188(2): 220-230.

4. Carteaux G, Lyazidi A, Cordoba-Izquierdo A, Vignaux L, Jolliet P, Thille AW, et al. Patient-ventilator asynchrony during noninvasive ventilation: a bench and clinical study. Chest 2012;142(2):367-376.

5. O'Donnell DE, Parker CM. COPD exacerbations. 3: Pathophysiology. Thorax 2006;61(4):354-361.

6. Aubier M, Murciano D, Fournier M, Milic-Emili J, Pariente R, Derenne JP. Central respiratory drive in acute respiratory failure of patients with chronic obstructive pulmonary disease. Am Rev Respir Dis 1980;122(2):191-199.

7. Smith TC, Marini JJ. Impact of PEEP on lung mechanics and work of breathing in severe airflow obstruction. J Appl Physiol 1988; 65(4):1488-1499.

8. Rittayamai N, Katsios CM, Beloncle F, Friedrich JO, Mancebo J, Brochard L. Pressure-controlled vs volume-controlled ventilation in acute respiratory failure: a physiology-based narrative and systematic review. Chest 2015;148(2):340-355.

9. Jaber S, Sebbane M, Verzilli D, Matecki S, Wysocki M, Eledjam JJ, Brochard L. Adaptive support and pressure support ventilation behavior in response to increased ventilatory demand. Anesthesiology 2009;110(3):620-627.

10. Briones Claudett KH, Briones Claudett M, Chung Sang Wong M, Nuques Martinez A, Soto Espinoza R, Montalvo M, et al. Noninvasive mechanical ventilation with average volume assured pressure support (AVAPS) in patients with chronic obstructive pulmonary disease and hypercapnic encephalopathy. BMC Pulm Med 2013; $13: 12$.

11. Cao Z, Luo Z, Hou A, Nie Q, Xie B, An X, et al. Volume-targeted versus pressure-limited noninvasive ventilation in subjects with acute hypercapnic respiratory failure: a multicenter randomized controlled trial. Respir Care 2016;61(11):1440-1450.

12. Contou D, Fragnoli C, Córdoba-Izquierdo A, Boissier F, Brun-Buisson C, Thille AW. Noninvasive ventilation for acute hypercapnic respiratory failure: intubation rate in an experienced unit. Respir Care 2013;58(12):2045-2052. 